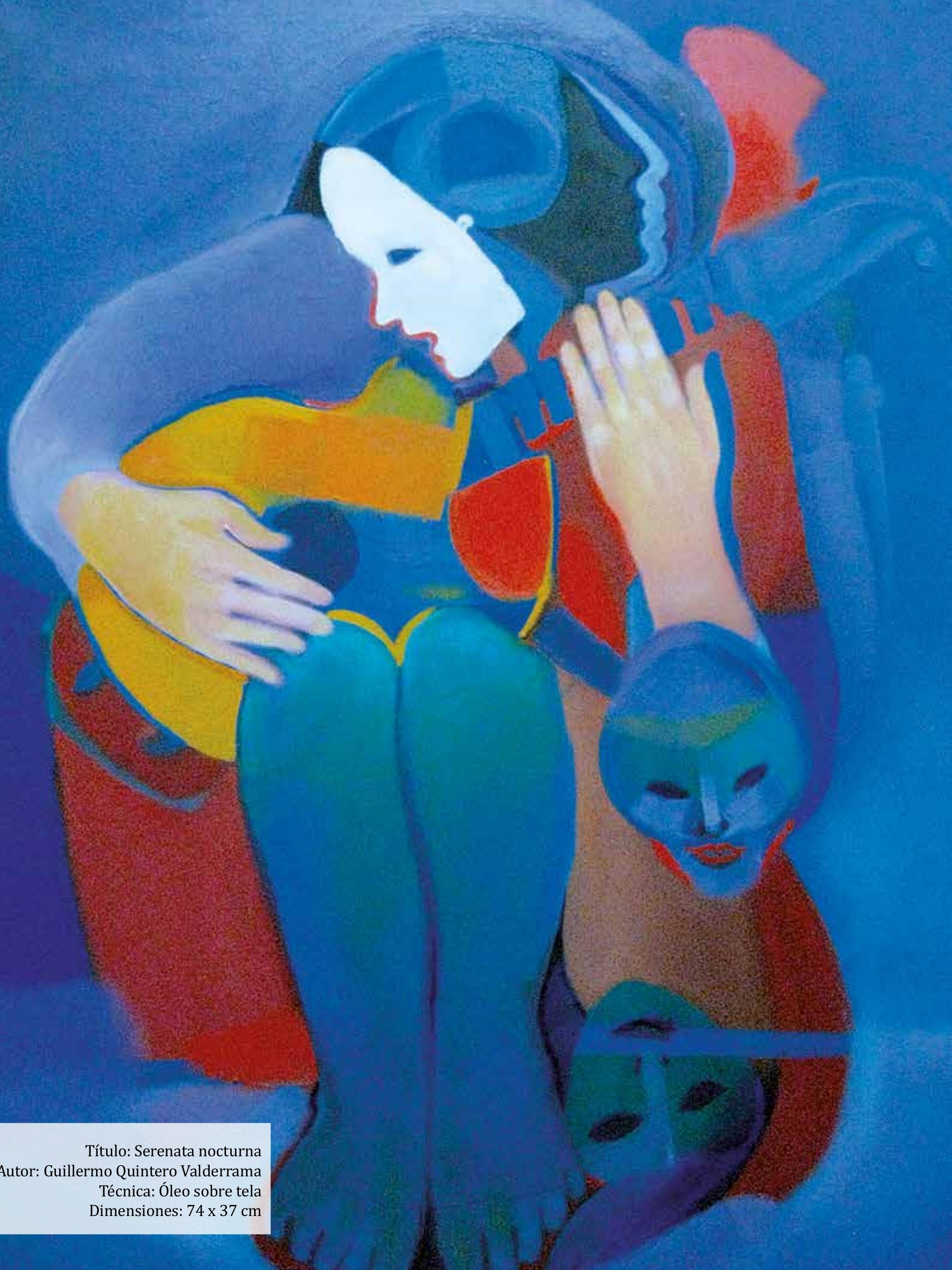




\section{A propósito de nuestros 25 años}

$\mathrm{H}$ ace un cuarto de siglo nació esta revista como un escenario para la discusión y difusión de la producción sobre y desde la Pedagogía. Con este número quisimos celebrar ese acontecimiento intelectual convocando a investigadores de distintos países, idiomas y perspectivas para reflexionar sobre la Pedagogía, sus conceptos y sus relaciones con otros saberes. El resultado es un panorama de los problemas, discusiones y elaboraciones actuales desde ópticas diversas y en el cual se perciben ecos de las principales tradiciones pedagógicas (francesa, alemana y crítica-anglo/latinoamericana).

Hoy ratificamos nuestra apuesta por mantener un espacio editorial para la difusión del saber pedagógico en su diversidad, lo que en otras palabras significa una contribución a la consolidación de un Campo Conceptual de la Pedagogía. Entendemos que este es un propósito central para la Facultad de Educación de la Universidad Pedagógica Nacional en un momento en el que, por una parte, desde diversos escenarios, se reconoce la importancia de la educación, de la formación, del aprendizaje permanente como estrategia para enfrentar diversas problemáticas de orden social, cultural, político y económico; esto es lo que los colegas europeos denominan educacionalización, los anglosajones learning society, y algunos otros sociedad pedagógica o pedagogización social. Por otra parte, emergen y cobran fuerza propuestas como las de "hackear" la educación y la escuela o en el que se abren paso movimientos como home schooling. ¿Son unos y otros muestras del fortalecimiento de la(s) pedagogía(s) o, por el contrario, de su crisis y decadencia?

Para discutir sobre estos y otros asuntos que involucran el pasado, presente y porvenir de la Pedagogía seguirá abierta nuestra revista. Desde aquí queremos contribuir no sólo con la formación de los maestros sino con el análisis y comprensión de los problemas educativos y pedagógicos del país en un periodo crucial de nuestra historia.

Carlos Ernesto Noguera-Ramírez

Director 